\title{
Complex chest wall surgery to prevent vascular complications after immunotherapy and radiation treatment
}

\author{
James J. Choi, MD, ${ }^{a}$ Robert J. Allen, Jr, MD, ${ }^{b}$ Manjit S. Bains, MD, ${ }^{a}$ Marc A. Cohen, MD, MPH, \\ Yao Yu, MD, ${ }^{\mathrm{d}}$ Nassrene Elmadhun, MD, ${ }^{\mathrm{a}}$ David R. Jones, $\mathrm{MD},{ }^{\mathrm{a}}$ and Gaetano Rocco, $\mathrm{MD},{ }^{\mathrm{a}}$ New York, NY
}

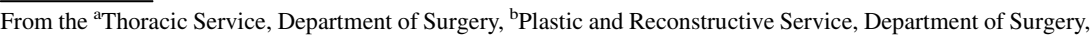
${ }^{\mathrm{c}} \mathrm{Head}$ and Neck Service, Department of Surgery, and ${ }^{\mathrm{d} D e p a r t m e n t ~ o f ~ R a d i a t i o n ~ O n c o l o g y, ~ M e m o r i a l ~ S l o a n ~}$ Kettering Cancer Center, New York, NY.

This study was supported, in part, by National Cancer Institute Cancer Center Support Grant P30 CA008748.

Disclosures: Dr Rocco has financial relationships with Scanlan. Dr Jones serves as a senior medical advisor for Diffusion Pharmaceuticals and a consultant for Merck and AstraZeneca. All other authors reported no conflicts of interest.

The Journal policy requires editors and reviewers to disclose conflicts of interest and to decline handling or reviewing manuscripts for which they may have a conflict of interest. The editors and reviewers of this article have no conflicts of interest.

Received for publication July 29, 2020; revisions received July 29, 2020; accepted for publication Aug 10, 2020; available ahead of print Aug 15, 2020.

Address for reprints: Gaetano Rocco, MD, FRCSEd, Thoracic Service, Department of Surgery, 1275 York Ave, \#861, New York, NY 10065 (E-mail: roccog@mskcc.org).

JTCVS Techniques 2020;4:329-31

2666-2507

Copyright $\odot 2020$ The Authors. Published by Elsevier Inc. on behalf of The American Association for Thoracic Surgery. This is an open access article under the CC BY-NC-ND license (http://creativecommons.org/licenses/bync-nd/4.0/).

https://doi.org/10.1016/j.xjtc.2020.08.014
}

A 64-year-old woman with diabetes presented with extensive destruction of the right anterior chest wall and thoracic inlet. A computed tomographic scan of the chest showed a large necrotic mass $(20 \times 20 \mathrm{~cm})$, with marked destruction of the right clavicle and focal destruction of the manubrium (Figure 1). Biopsy yielded poorly differentiated squamous cell carcinoma with unknown programmed death-ligand 1 status. The patient gave written informed consent for the publication of this case.

The initial treatment plan was to administer ongoing cemiplimab $350 \mathrm{mg}$ intravenously every 3 weeks, with a total of 3 cycles of concurrent Quad Shot radiotherapy every 3 to 6 weeks. One cycle of Quad Shot radiotherapy consists of 14 Gy of radiation given in 4 fractions over 2 days.

Surgical referral was not considered initially, but after only 2 doses of cemiplimab and 1 intervening cycle of radiotherapy, subsequent cycles were withheld and surgery was pursued. Repeat imaging at this time showed that, although there was regression of the tumor superficially, the tumor continued to contact the subclavian vessels deeper in the chest wall, and there was new erosion of the first rib. With anticipation of imminent erosion into the vascular bundle and possible catastrophic bleeding, surgery was performed 6 weeks after the last dose of cemiplimab. The mass was resected en bloc with the manubrium, anterior segments of ribs 1 to 3 , and remnants of the right clavicle (Figure 2). Resection was started from the left parasternal line, and the costal cartilages of ribs 1 and 2 were removed. The manubrium was then

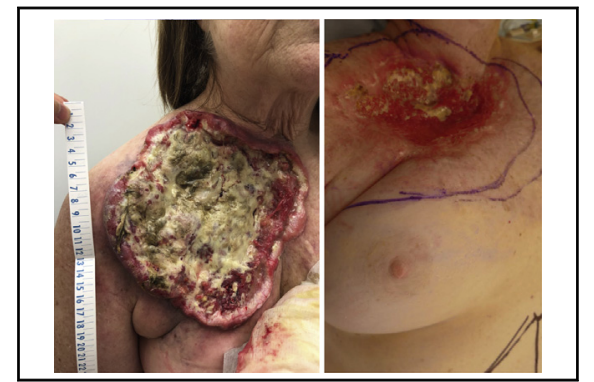

Tumor seen before immunotherapy and radiation and then at the time of surgical resection.

CENTRAL MESSAGE

Chest wall surgery after immunotherapy and radiation can

provide cure, prevent cata-

strophic complications, reduce

the duration of immunotherapy, and allow verification of depth of response to therapy.

See Commentaries on pages 332 and 334

transected transversely at the level of the third costal cartilage, and the right anterior segments of ribs 1 to 3 and the remnants of the right clavicle were removed. Both the right brachiocephalic vein and the subclavian vein were spared. The chest wall was then reconstructed using an acellular collagen matrix patch, which was secured to the lateral cut ends of ribs 2 and 3 and around rib 4 on the right, and to the anterior ribs 2 and 3, as well as the sternoclavicular joint on the left. The surgical bed was then covered by a conjoined bipedicled transverse rectus abdominis muscle flap. The postoperative course was uneventful, and the patient remains disease free 14 months after surgery. Postresection pathologic evaluation showed a residual mass measuring $9.0 \times 8.5 \mathrm{~cm}$, with extensive treatment necrosis and no viable tumor remaining. Follow-up computed tomography of the chest showed a well-healed resection bed with intact chest wall integrity.

Cemiplimab is a monoclonal antibody against programmed death 1 receptor. Consistent with the experience with our patient, cemiplimab has demonstrated safety and 

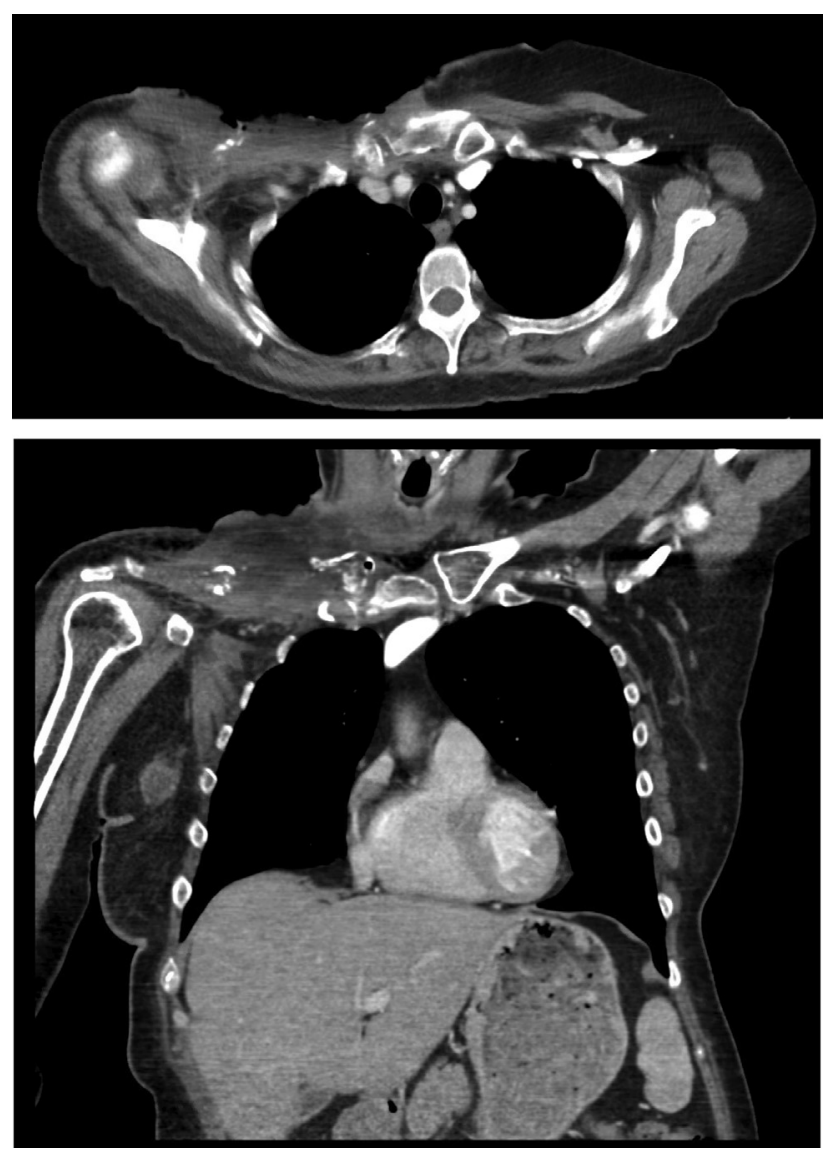

FIGURE 1. Computed tomography scan of the chest shows the sizeable mass of the right chest wall and thoracic inlet. Top panel, There is exposed soft tissue and muscle with focal destruction of the manubrium, as well as almost complete destruction of the right clavicle. The close proximity of tumor to the common carotid artery and the brachiocephalic vein can be seen. Bottom panel, The near-complete destruction of the right clavicle is observed.

efficacy in the treatment of cutaneous squamous cell carcinomas but has an overall response rate of only $44 \% .^{1,2}$ Surgery was primarily necessary to avoid possible catastrophic hemorrhage from the vascular axis at the thoracic inlet. As a secondary advantage, surgical resection helped to ascertain the so-called depth of response (DoR) after treatment, which is defined as the percentage of target tumor shrinkage, on the basis of the longest diameter or reconstructed volume, observed at the lowest point (nadir), compared with baseline. ${ }^{3}$ DoR is used as an individualized measure of treatment efficacy and is a controversial surrogate for long-term outcomes. ${ }^{4}$ In our case, immunotherapy and radiation provided shrinkage of the tumor bulk superficially, but there was minimal effect deeper in the chest wall, demonstrating a nonhomogenous DoR. A third and unexpected outcome in our case was the absence of malignancy in the postresection tumor. This fact would have remained unknown without surgical resection, and immunotherapy would have been continued indefinitely until it became ineffective or limited by patient toxicity. Although difficult, surgery should be pursued when technically feasible to optimize the treatment duration of systemic therapy and to minimize the side effects and costs related to immunotherapy.

Aspects of immunotherapy that often go unnoticed are the peritumoral inflammatory response that occurs and the possible disruption of anatomic planes. In our patient, the tumor underwent resection 6 weeks after induction cemiplimab and 8 weeks after radiation therapy. The tumor was clearly palpable, and a margin from the surrounding tissues could be delineated, keeping the resection flush to the vascular axis at the thoracic inlet. In fact, despite the inflammation, a millimetric surgical plane remained between the mass and the thoracic inlet vessels that allowed for safe resection of the mass.

Among recently introduced materials, acellular collagen matrix patches should not be overlooked as a viable prosthesis for chest wall reconstruction. It is pliable but at the same time confers sufficient rigidity to the reconstruction; the patch is straightforward to place and can be left in place if infection occurs. It provides a firm and stable platform that, over time, will be incorporated with the surrounding tissues, thus representing a good alternative to synthetic mesh. ${ }^{5}$ 

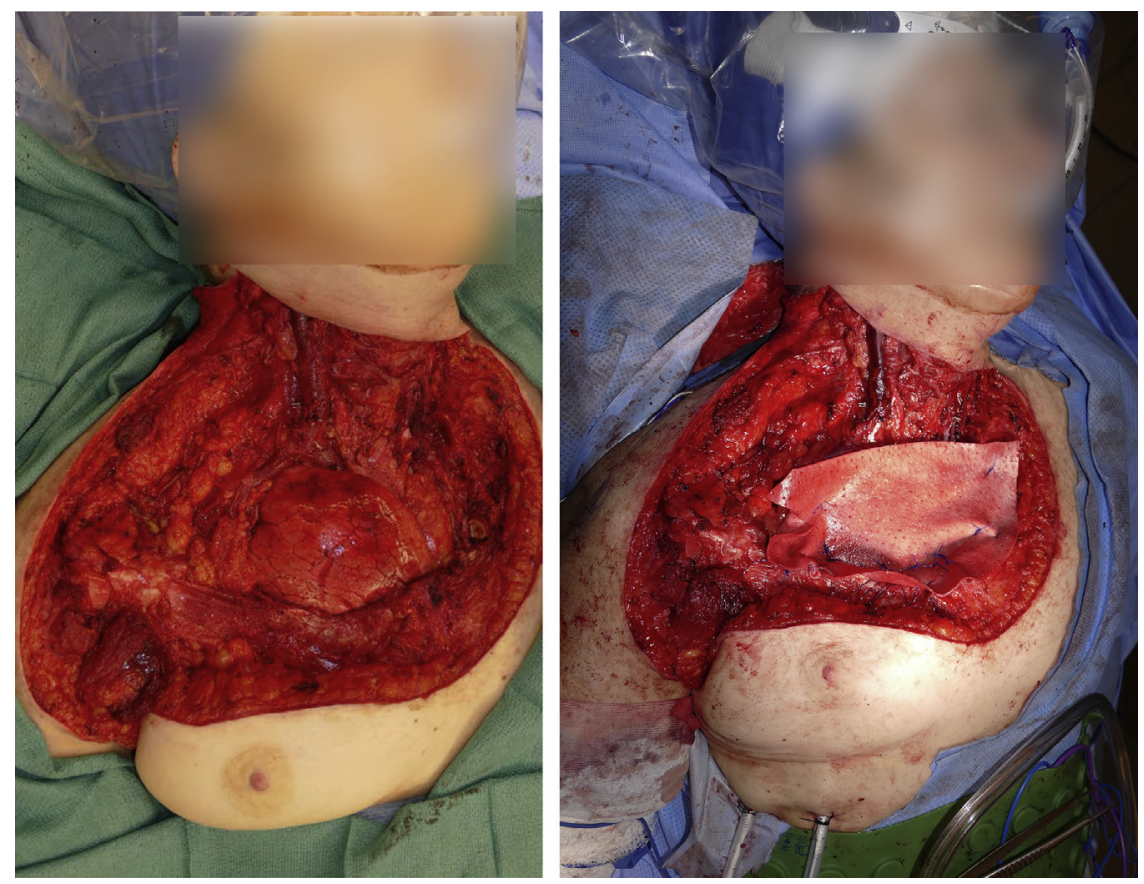

FIGURE 2. Despite marked reduction in tumor size with immunotherapy and radiation, a complex surgical resection was necessary. Left panel, The surgical resection bed is seen after removal of the tumor, with the right subclavian and internal jugular vein in view, with the apex of the right lung and cut edges of the anterior left ribs. Right panel, The acellular collagen matrix patch sutured around the fourth rib and the lateral cut ends of ribs 2 and 3 on the right, and the anterior ribs 2 and 3, as well as the sternoclavicular joint on the left.

\section{References}

1. Migden MR, Rischin D, Schmults CD, Guminski A, Hauschild A, Lewis KD, et al, PD-1 blockade with cemiplimab in advanced cutaneous squamous-cell carcinoma. N Engl J Med. 2018;379:341-51.

2. Migden MR, Khushalani NI, Chang ALS, Lewis KD, Schmults CD, HernandezAya L, et al. Cemiplimab in locally advanced cutaneous squamous cell carcinoma: results from an open-label, phase 2, single-arm trial. Lancet Oncol. 2020;21: 294-305.

3. Mansmann UR, Laubender RP. Methodologic diligence is needed to define and validate tumor-size response metrics to predict overall survival in first-line metastatic colorectal cancer. J Clin Oncol. 2013;31:4373-4.

4. Lee CK, Lord S, Marschner I, Wu YL, Sequist L, Rosell R, et al. The value of early depth of response in predicting long-term outcome in EGFR-mutant lung cancer. $J$ Thorac Oncol. 2018;13:792-800.

5. Rocco G. Chest wall resection and reconstruction according to the principles of biomimesis. Semin Thorac Cardiovasc Surg. 2011;23:307-13. 